\title{
SEGURANÇA DO PACIENTE NO PROCESSO DE DOAÇÃO E TRANSPLANTE DE ÓRGÃOS E TECIDOS
}

\author{
Aline Lima Pestana Magalhães ${ }^{1}$, Gabriela Marcellino de Melo Lanzoni ${ }^{1}$, Neide da Silva Knihss ${ }^{1}$, Elza Lima da \\ Silva ${ }^{2}$, Alacoque Lorenzini Erdmann ${ }^{3}$
}

RESUMO: Objetivou-se apresentar aspectos inovadores para a prática profissional do enfermeiro, no que se refere ao diagnóstico de morte encefálica no processo de doação e transplante de órgãos e tecidos, abordando as interfaces entre a gerência do cuidado e a segurança do paciente. Enfatiza-se a padronização de processos, utilizada para promover agilidade, redução das perdas por parada cardíaca com aumento concomitante das doações reais, e diminuição do tempo entre o primeiro exame clínico e o explante. Permite que a equipe reconheça as anormalidades e faça as correções necessárias em tempo hábil. Assim, vislumbra-se que a segurança do paciente deve subsidiar as tomadas de decisão e intervenções de gestão, de modo a qualificar a prática de cuidado.

DESCRITORES: Gerência; Cuidados de enfermagem; Segurança do paciente; Obtenção de órgãos e tecidos; Transplantes.

\section{PATIENT SAFETY IN THE PROCESS OF ORGAN AND TISSUE DONATION AND TRANSPLANT}

\begin{abstract}
This article aims to present innovative aspects for the professional practice of the nurse, regarding the diagnosis of brain death in the process of donation and transplantation of organs and tissues, addressing the interfaces between the care management and patient safety. Emphasis is placed on the standardization of processes, used to promote speed, reduction in losses from cardiac arrest with a concurrent increase in actual donations, and reduction of time between the first clinical examination and harvesting of the organ. It allows the team to recognize abnormalities and make the necessary corrections in time. Thus, it is seen that patient safety should be a basis for management's decision-making and interventions, so as to make the care practice of adequate quality. DESCRIPTORS: Management; Nursing Care; Patient Safety; Tissue and Organ Procurement; Transplants.
\end{abstract}

\section{SEGURIDAD DEL PACIENTE EN EL PROCESO DE DONACIÓN Y TRASPLANTE DE ÓRGANOS Y TEJIDOS}

RESUMEN: Estudio cuyo objetivo fue presentar aspectos innovadores para la práctica profesional del enfermero acerca del diagnóstico de muerte encefálica en el proceso de donación y trasplante de órganos y tejidos, considerándose las relaciones entre la administración del cuidado y la seguridad del paciente. Se destaca la estandarización de procesos, utilizada para promover agilidad, reducción de pérdidas por parada cardíaca con aumento concomitante de las donaciones reales, así como disminución del tiempo entre el primer examen clínico y el explante. Eso posibilita que el equipo reconozca las anormalidades e haga las correcciones necesarias en tiempo hábil. De ese modo, se constata que la seguridad del paciente debe subsidiar las decisiones e intervenciones de gestión, a fin de calificar la práctica de cuidado.

DESCRIPTORES: Gerencia; Cuidados de enfermería; Seguridad del paciente; Obtención de órganos y tejidos; Trasplantes.

${ }^{1}$ Enfermeira. Doutora em Enfermagem. Docente do Departamento de Enfermagem da Universidade Federal de Santa Catarina. Florianópolis, SC, Brasil.

${ }^{2}$ Enfermeira. Doutora em Fisiopatologia Clínica e Experimental. Docente de Enfermagem da Universidade Federal do Maranhão. São Luís, MA, Brasil.

${ }^{3}$ Enfermeira. Doutora em Filosofia da Enfermagem. Docente de Enfermagem da Universidade Federal de Santa Catarina. Florianópolis, SC, Brasil. 


\section{INTRODUÇÃO}

A segurança do paciente é princípio básico e requisito para a qualidade do cuidado, devendo ser valorizada como direito do paciente, e compromisso ético dos profissionais e das instituições de saúde. É definida como a redução do risco de danos desnecessários associados ao cuidado de saúde, até um mínimo aceitável, pois, considerando-se a complexidade dos procedimentos e tratamentos em saúde, o potencial para o dano é real(1-2).

O Brasil possui atualmente um dos maiores programas público de transplantes de órgãos e tecidos do mundo. No contexto internacional, o país destaca-se como o segundo em número absoluto de transplantes renais (5.635), com os Estados Unidos em primeiro (17.107) ${ }^{(3-4)}$. No contexto da doação e transplante de órgãos e tecidos, a segurança do potencial doador e do processo deve ser certificada em cada etapa, mas, devido à sua relevância, objetiva-se apresentar aspectos inovadores para a prática profissional do enfermeiro, no que se refere ao diagnóstico de morte encefálica (ME) no processo de doação e transplante de órgãos e tecidos.

\section{ARTICULANDO A GERÊNCIA DO CUIDADO COM A SEGURANÇA DO PACIENTE NO PROCESSO DE DOAÇÃO E TRANSPLANTE}

A segurança no diagnóstico de ME consiste em fazer a detecção precoce, por meio de duas avaliações clínicas neurológicas e da realização do exame gráfico complementar. A avaliação clínica deve ser realizada em dois momentos, respeitando o intervalo de tempo estabelecido para cada faixa etária do potencial doador: de sete dias a dois meses incompletos, deve-se repetir o exame a cada 48 horas; de dois meses a um ano incompleto, repetir a cada 24 horas; de um ano a dois anos incompletos, a cada 12 horas; e acima de dois anos, a cada 6 horas $^{(5-6)}$.

A causa do coma deve ser conhecida, sendo excluídas a hipotermia e o uso de drogas depressoras do sistema nervoso central. Além disso, os exames clínicos devem ser realizados por médicos diferentes, que não podem ser integrantes da equipe de remoção e transplante, sendo um obrigatoriamente neurologista. Os exames complementares precisam demonstrar ausência de atividade elétrica ou de atividade metabólica cerebral ou de perfusão sanguínea. Os dados clínicos e dos exames complementares devem ser registrados no Termo de Declaração de Morte Encefálica e estar devidamente assinado pelos médicos que avaliaram o paciente ${ }^{(5-6)}$. Os familiares devem ser acolhidos e estar cientes de todo o processo de diagnóstico de ME.

No processo de doação, a segurança está em fazer a avaliação e o cuidado ao potencial doador minuciosamente. É preconizado que esse paciente seja mantido sob cuidados intensivos, pois requer atenção profissional especializada de forma contínua, materiais específicos e tecnologias para monitorização e tratamento. Acrescenta-se que, além dos profissionais deste setor, existem os profissionais das Comissões Intra-Hospitalares de Doação de Órgãos e Tecidos para Transplantes (CIHDOTT) e da Central de Transplantes, que auxiliam na condução da avaliação e dos cuidados ao potencial doador.

As avaliações clínicas e laboratoriais são necessárias para obtenção de um enxerto de qualidade, bem como para evitar a transmissão de enfermidades infecciosas e neoplásicas ao receptor. Estas ocorrem por meio do exame físico detalhado e análise clínica minuciosa (exames laboratoriais, como hemograma completo, eletrólitos, tipagem sanguínea; exame da função renal, pancreática, hepática, pulmonar, cardiológica; sorologias para doenças infectocontagiosas e culturas biológicas) ${ }^{(7-8)}$.

No processo de doação, as demandas relacionadas às avaliações supracitadas contemplam a importante etapa de "validação do potencial doador", a qual deve ser complementada pela coleta de informações com a equipe que assiste o paciente em $\mathrm{ME}$, bem como junto dos familiares. Assim, os profissionais que atuam na CIHDOTT buscam identificar fatos, indícios e detalhes que possam revelar contraindicações absolutas ou relativas, visando garantir qualidade e segurança para o processo ${ }^{(7-8)}$.

O cuidado ao potencial doador deve ser rigoroso, no sentido de otimizar a perfusão tecidual, para assegurar a viabilidade e a qualidade dos órgãos e tecidos. Alguns cuidados que devem ser realizados: 
manutenção térmica, hemodinâmica e do equilíbrio eletrolítico, assim como a reposição hormonal e a aplicação de regime ventilatório adequado ${ }^{(9)}$. O cuidado efetivo do potencial doador possibilita a perfusão/oxigenação adequada dos órgãos, favorecendo inclusive a realização tranquila da entrevista junto dos familiares.

Após a constatação da ME e descartadas as contraindicações clínicas que representam riscos aos receptores, o paciente é considerado potencial doador de órgãos e tecidos. Nesse momento, a família deve ser comunicada pelo médico responsável da irreversibilidade do quadro clínico do paciente. Na sequência, os coordenadores de transplante, na maioria enfermeiros, que trabalham na CIHDOTT ou nos Serviços de Procura de Órgãos e Tecidos, realizam a entrevista familiar para abordar a doação ${ }^{(10)}$. Após a autorização familiar, é realizado o processo de remoção e distribuição dos órgãos.

A segurança no transplante está relacionada com as etapas bem conduzidas e documentadas do explante, acondicionamento e transporte dos órgãos e/ou tecidos.

Para cada uma dessas etapas referidas, existem ações e procedimentos que necessitam ser seguidos, a fim de assegurar a validade do processo, de modo a não prejudicar os pacientes receptores e familiares envolvidos no processo ${ }^{(8)}$.

O enfermeiro, ao longo dos anos, é considerado o profissional com maior habilidade para interagir nesse cenário e gerenciar esse processo. Ele é capaz de interagir com a equipe multiprofissional e a família, priorizar e tomar decisões em tempo hábil, garantindo que o cuidado desenvolvido nesse processo possa se tornar efetivo, seguro e com qualidade ${ }^{(11)}$.

Para facilitar e favorecer a segurança no diagnóstico de $\mathrm{ME}$, no processo de doação e no transplante, a Central de Transplantes de Santa Catarina organizou instrumentos gerenciais, para que, em cada nível de cuidado (unidade de terapia intensiva, emergência, CIHDOTT e central), sejam seguidas as mesmas etapas para uniformizar e direcionar a assistência ao paciente em $\mathrm{ME}$, identificar oportunidades de melhorias no que se refere a demandas administrativas, bem como aperfeiçoar o cuidado direto.

Segundo dados do Registro Brasileiro de Transplantes, até junho de 2016 o Brasil realizou 3.823 transplantes de órgãos sólidos, sendo 657 de doador vivo e 3.166 de doador falecido. As Regiões Sul e o Sudeste do Brasil são as que concentram o maior número de transplantes. O Estado de Santa Catarina é líder nacional de doação de órgãos, com a melhor taxa de doadores efetivos: 34,9 por milhão de habitantes, consolidando-se com a melhor taxa de doação no país. Esta taxa é comparável às melhores dos países desenvolvidos, tal como a Espanha, que apresenta em torno de 35 doadores por milhão de habitantes ${ }^{(3-4)}$.

Estudo qualitativo desenvolvido em Santa Catarina ${ }^{(11)}$ mostrou que a gerência do cuidado, no processo de doação e transplante de órgãos e tecidos, está pautada em um tripé, que consolida a segurança do paciente doador e receptor como elemento fundamental e transversal ao processo, por meio de educação permanente, padronização e monitoramento dos indicadores do processo (como avaliação dos indicadores de doação e transplante, para avaliar o desempenho das CIHDOTT e da central; identificação da não conformidades e realização de auditoria do processo).

Considerando a ênfase no processo de doação e transplante, a padronização tem sido recomendada internacionalmente como ferramenta que torna cada membro da equipe mais eficiente, fazendo que tenha clareza da sua responsabilidade no trabalho ${ }^{(12)}$.

Especificamente sobre esta questão, destaca-se que, na segurança no transplante, a Central de Transplantes de Santa Catarina, juntamente das CIHDOTT e dos cirurgiões, desenvolveu instrumentos gerenciais para padronizar as etapas de cuidados para a manutenção do potencial doador, do explante, acondicionamento e transporte dos órgãos e tecidos. Como impacto dessas ações, o processo de cuidado ficou mais ágil, as perdas por parada cardíaca reduziram-se, havendo aumento concomitante das doações reais e diminuição do tempo entre o primeiro exame clínico e o explante ${ }^{(7)}$.

Procedimentos Operacionais Padrão (POP) documentam o modo como o profissional deve agir em cada etapa do processo, permitindo que todos "falem a mesma língua"(11). Também, a padronização do trabalho é uma estratégia utilizada pelo pensamento Lean que tem como objetivo estabelecer uma sequência padrão de trabalho, que deve ser seguida toda vez que uma determinada atividade for 
desenvolvida, permitindo que a equipe reconheça as anormalidades e faça as correções necessárias em tempo real ${ }^{(13)}$.

\section{CONSIDERAÇÕES FINAIS}

A segurança do paciente necessita transitar em todos os cenários de cuidado, uma vez que a assistência produzida e consumida é resultante de relações e que, na doação e no transplante de órgãos e tecidos, acontece em três níveis diferentes: central de transplantes, CIHDOTT e nos serviços de unidade de terapia intensiva e emergência. Deste modo, possibilita a ocorrência de erros e/ou eventos adversos no processo da gerência do cuidado, caso este não seja bem conduzido.

Uma estratégia enfatizada pela Política Nacional de Segurança do Paciente é a padronização dos processos articulada à Educação Permanente, para potencializar a tomada de decisão segura e qualificada, bem como fortalecer intervenções de gestão transformadoras da prática de cuidado.

\section{- REFERÊNCIAS}

1. Ministério da Saúde (BR). Portaria n. 529, de $1^{\circ}$ de abril de 2013. Institui o Programa Nacional de Segurança do Paciente. Diário Oficial da União, Brasília, 2 abr. 2013.

2. de Souza VS, Kawamoto AM, de Oliveira JLC, Tonini NS, Fernandes LM, Nicola AL. Erros e eventos adversos: a interface com a cultura de segurança dos profissionais de saúde. Cogitare Enferm. 2015;20(3):475-82.

3. Associação Brasileira de Transplante de Órgãos (ABTO). Registro Brasileiro de Transplantes. Dados Numéricos da doação de órgãos e transplantes realizados por estado e instituição no período: janeiro/junho de 2016. São Paulo: ABTO; 2016.

4. Associação Brasileira de Transplante de Órgãos (ABTO). Registro Brasileiro de Transplantes. Dimensionamento dos Transplantes no Brasil e em cada estado (2008-2015). São Paulo: ABTO; 2015.

5. Pestana AL, dos Santos JLG, Erdmann RH, da Silva EL, Erdmann AL. Pensamento Lean e cuidado do paciente em morte encefálica no processo de doação de órgãos. Rev. esc. enferm. USP. [Internet] 2013;47(1) [acesso em 25 fev 2016]. Disponível: http://dx.doi.org/10.1590/S0080-62342013000100033.

6. Conselho Federal de Medicina (CFM). Resolução n. 1.480, de 8 de agosto de 1997. Estabelece os critérios para caracterização de morte encefálica. Brasília: CFM; 1997.

7. Freire ILS, de Vasconcelos QLDAQ, Torres GV, de Araújo EC, Costa IKF, Melo GSM. Estrutura, processo e resultado da doação de órgãos e tecidos para transplante. Rev. bras. enferm. 2015;68(5):837-45.

8. Associação Brasileira de Transplante de Órgãos (ABTO). Diretrizes Básicas para captação e retirada de múltiplos órgãos e tecidos da Associação Brasileira de Transplante de Órgãos. São Paulo: ABTO; 2009.

9. Westphal GA, Zaclikevis VR, Vieira KD, Cordeiro RB, Horner MBW, de Oliveira TP, et al. Protocolo gerenciado de tratamento do potencial doador falecido reduz incidência de parada cardíaca antes do explante dos órgãos. Rev. bras. ter. intensiva. 2012;24(4):334-40.

10. dos Santos MJ, Massarollo MCKB, de Moraes EL. Entrevista familiar no processo de doação de órgãos e tecidos para transplante. Acta paul. enferm. 2012;25(5):788-94.

11. Magalhães ALP. Gerenciando o cuidado de enfermagem no processo de doação e transplantes de órgãos e tecidos na perspectiva do pensamento lean [tese]. Florianópolis (SC): Universidade Federal de Santa Catarina; 2015.

12. Arakelian E, Gunningberg L, Larsson J. How operating room efficiency is understood in a surgical team: a qualitative study. Int J Qual Health Care. 2011;23(1):100-6.

13. Brackett T, Comer L, Whichello R. Do Lean practices lead to more time at the bedside?. J Healthc Qual. 2013;35(2):7-14. 